\title{
Investigating the Prevalence of Anorectal Complications and the Factors Influencing it During Pregnancy and After Child Birth in Natural Delivery and Cesarean Among The Pregnant Women
}

\author{
Sima Ghasemzade ${ }^{1}$, Mehri Seifoleslami², \\ Pedram Bobe Jame ${ }^{3}$ and Aghdas Safari ${ }^{1 *}$
}

\begin{abstract}
${ }^{1}$ Department of Gynecology, Imam Reza Hospital , AJA University of Medical Sciences, Tehran, Iran. ${ }^{2}$ Department of Gynecology, Khanevadeh Hospital, AJA University of Medical Sciences, Tehran, Iran. ${ }^{3}$ Medical Student, AJA University of Medical Sciences, Tehran, Iran.
\end{abstract}

http://dx.doi.org/10.13005/bbra/2046

(Received: 26 January 2016; accepted: 27 February 2016)

\begin{abstract}
Anorectal disorders are among the most common digestive complications among pregnant women. Due to the physical and psychological recurring problems they cause for patients, these complications will result in a significant reduction in the quality of the life of those afflicted. In this study, we will seek to study the prevalence of Anorectal complications and the factors influencing it during pregnancy and after child birth in natural delivery and Cesarean. This research is an observatory study based on the descriptive and sectional methods. 200 pregnant women resorting to the maternity ward of Golestan and Besat Family Hospital in the years 2009 and 2010 were selected and the existence of Hemorrhoids and Fissure was measured through inspection in three phases before and during pregnancy and during childbirth and one month after it. The results were recorded in questionnaires. Other variables such as parity, type of the previous and current childbirth, previous experience of anal disorders, weight of the baby and length of the second phase of Lieber and their relationship with the prevalence of Anorectal disorders were also taken into consideration. SPSS software was utilized to analyze the data. A significant statistical relationship was observed between parity and Hemorrhoids and Fissure in post-delivery phase and the highest level of it was observed in people with parity levels above $2(p=0.0001)$. A significant statistical relationship was seen between type of the previous childbirth and Hemorrhoids in post-delivery phase and the highest level was observed during the post-delivery period $(p=$ $0.008)$. The same type of relationship was also observed with Fissure $(p=0.0001)$. A significant statistical relationship was also observed between previous records of anal disorders and Hemorrhoids and Fissure in post-delivery phase, and its highest level was seen in postdelivery phase in people with a past records of anal disorders $(p=0.0001)$. No significant statistical association was seen between the current type of child delivery and Hemorrhoids and Fissure, although its highest level was observed in post-delivery phase in people who had natural childbirth $(p>0.05)$. A significant statistical association was observed between the weight of the baby and Hemorrhoid and Fissure in post-delivery phase and its highest level was seen in post-delivery phase in children over the weight of 3700 grams $(p=0.0001)$. A significant statistical association was observed between the length of the second phase of natural childbirth and Hemorrhoid and Fissure in post-delivery phase. The highest levels of Fissure in post-delivery phase were observed in people with the length of more than 50 minutes $(p=0.0001)$. In this study, a significant statistical relationship was observed between post-delivery Anorectal disorders with parity, type of previous childbirth, past experience of anal disorders, weight of the baby, and the length of the second phase of Lieber. No significant statistical association was observed between type of the current childbirth (Cesarean or Natural) and the above mentioned disorders.
\end{abstract}

Keywords: Hemorrhoid, Fissure, Natural childbirth, Cesarean childbirth.

\footnotetext{
* To whom all correspondence should be addressed.

Tel.: 00989122959230; E-mail : safari1344@yahoo.com
} 
Anorectal disorders including Hemorrhoid and Fissure are among the most common digestive complications among pregnant women. Due to the recurring physical and psychological problems they cause for the patient, these disorders which are observed among 30 to 50 percent of women can cause a significant reduction in the life quality of those afflicted with them $^{1-10}$. It is hypothesized that pregnancy, due to the rise of vascular pressure and abdominal hole pressure, may contribute to the rise of Hemorrhoid. However, there is no such hypothesis concerning Fissure. Although it has been reported that pregnant women exhibit higher levels of Fissure as compared to the public, however; the cause of it is not clear ${ }^{1}$.Other reasons such as hormonal changes, excessive weight gain of mother, lack of movement, consuming iron supplements (which aggravate constipation) have been mentioned as the causes of great prevalence of this disease during the pregnancy period ${ }^{2,12}$. As for Fissure, it is less common than Hemorrhoid. This can be due to the severe pain and anal bleeding which make the patient see a doctor quickly. The other point about this disease is its progress which is due to its vicious cycle (pain, Sphincter contraction, Fissure intensification $)^{1,11,17,18}$. In several similar studies, the prevalence of Anorectal diseases (Hemorrhoid and Fissure) after childbirth was 20 to 40 percent. The most common cause of this is Dysshzya $^{4,7}$.

Based on the level of disease, various medical and surgical treatments have been proposed for Hemorrhoid and Fissure. Medical treatments are based upon dietary fibers ${ }^{1}$. The most common type of operation for Hemorrhoid is Hemorrhoidectomy. Other types of operations such as Sclerotherapy and Bandlygyshn are also used in some centers ${ }^{21}$. The operation for Fissure encompasses partial Sphincterotomy which improves the Fissure by reducing sphincter contraction $^{15,16}$. Considering the results of the previous studies and great prevalence of Anorectal disorders during pregnancy and the little attention doctors pay to this issue and since there was no similar research of this kind conducted in Iran, we set out to study the prevalence of this disease during pregnancy and after pregnancy and look at the factors which cause it.

\section{MATERIALSANDMETHOD}

This is an observational study based upon descriptive-sectional methods. 200 pregnant women resorting to the maternity ward of Golestan and Besat Family Hospital in the years 2009 and 2010 were selected and their demographic information was recorded in questionnaires. The existence of Hemorrhoids and Fissure was measured through inspection in three phases before and during pregnancy and during childbirth and one month after it. The results were recorded in questionnaires. The main goal of this research is to find the prevalence of Anorectal complications and the factors influencing it during the pregnancy and post childbirth period in natural childbirth and Cesarean. The variables studied included: age, level of education, occupation, parity, previous childbirth, current childbirth, last records of Hemorrhoid and Fissure, existence of Hemorrhoid in 3 phases of pre-pregnancy, during pregnancy, during childbirth and one month after childbirth. Finally when the required information concerning patients was gathered, data was analyzed using SPSS11. Chi square and Fischer tests were used.

A significant relationship was observed between parity and Hemorrhoid and Fissure in the post-childbirth phase and the highest level of that was observed in post-childbirth phase in people with a parity level above $2(\mathrm{p}=0.0001)$.

A significant relationship was observed between previous childbirth type and Hemorrhoid and Fissure in the post-childbirth phase and the highest level of that was observed in postchildbirth phase in people with previous natural childbirth ( $\mathrm{p}=0.0001)$.

A significant relationship was observed between past records of anal disorders and Hemorrhoid and Fissure in the post-childbirth phase and the highest level of that was observed in post-childbirth phase in people with previous records of anal disorders $(p=0.0001)$.

No significant statistical relationship was observed between the type of current childbirth type and Hemorrhoid and Fissure in post-childbirth phase, whereas the highest level of that in postchildbirth phase was reported among people with natural childbirth ( $\mathrm{p}>0.05)$.

A significant relationship was observed 
between the weight of the baby and Hemorrhoid and Fissure in the post-childbirth phase and the highest level of that was observed in postchildbirth phase in Macrosomia infants (above 3700 grams) $(p=0.0001)$.

A significant relationship was observed between the length of the second phase of natural childbirth and Hemorrhoid and Fissure in the postchildbirth phase and the highest level of that was observed in post-childbirth phase in people with a length of more than 50 minutes ( $\mathrm{p}=0.0001)$.

Table 1. The relationship between parity and Hemorrhoid

\begin{tabular}{|c|c|c|c|c|c|}
\hline \multicolumn{6}{|c|}{ Crosstab } \\
\hline & & & \multicolumn{2}{|c|}{$\begin{array}{c}\text { Hemorrhoid after } \\
\text { Pregnancy }\end{array}$} & \multirow[b]{2}{*}{ Total } \\
\hline & & & Pos & Neg & \\
\hline \multirow[t]{8}{*}{ Parity } & 0 & Count & 10 & 10 & 20 \\
\hline & & $\%$ within Parity & $50.0 \%$ & $50.0 \%$ & $100.0 \%$ \\
\hline & 1 & Count & 9 & 60 & 69 \\
\hline & & $\%$ within Parity & $13.0 \%$ & $87.0 \%$ & $100.0 \%$ \\
\hline & 2 & Count & 21 & 69 & 90 \\
\hline & & $\%$ within Parity & $23.3 \%$ & $76.7 \%$ & $100.0 \%$ \\
\hline & $>2$ & Count & 11 & 10 & 21 \\
\hline & & $\%$ within Parity & $52.4 \%$ & $47.6 \%$ & $100.0 \%$ \\
\hline \multirow[t]{2}{*}{ Total } & & Count & 51 & 149 & 200 \\
\hline & & $\%$ within Parity & $25.5 \%$ & $74.5 \%$ & $100.0 \%$ \\
\hline
\end{tabular}

Table 3. The relationship between records of Anorectal disorders and Hemorrhoid

\begin{tabular}{|c|c|c|c|c|c|}
\hline \multicolumn{6}{|c|}{ Crosstab } \\
\hline & & & \multicolumn{2}{|c|}{$\begin{array}{l}\text { Hemorrhoid after } \\
\text { Pregnancy }\end{array}$} & \multirow[b]{2}{*}{ Total } \\
\hline & & & Pos & Neg & \\
\hline \multirow{4}{*}{$\begin{array}{l}\text { Anal Disease } \\
\text { History }\end{array}$} & Pos & Count & 41 & 22 & 63 \\
\hline & & $\begin{array}{l}\% \text { within Anal } \\
\text { Disease History }\end{array}$ & $65.1 \%$ & $34.9 \%$ & $100.0 \%$ \\
\hline & Neg & Count & 10 & 127 & 137 \\
\hline & & $\begin{array}{l}\% \text { within Anal } \\
\text { Disease History }\end{array}$ & $7.3 \%$ & $92.7 \%$ & $100.0 \%$ \\
\hline \multirow[t]{2}{*}{ Total } & & Count & 51 & 149 & 200 \\
\hline & & $\begin{array}{l}\% \text { within Anal } \\
\text { Disease History }\end{array}$ & $25.5 \%$ & $74.5 \%$ & $100.0 \%$ \\
\hline
\end{tabular}

Table 5. The relationship between the weight of baby and Hemorrhoid

\begin{tabular}{|c|c|c|c|c|c|}
\hline \multicolumn{6}{|c|}{ Crosstab } \\
\hline & & & \multicolumn{2}{|c|}{$\begin{array}{l}\text { Hemorrhoid after } \\
\text { Pregnancy }\end{array}$} & \multirow[b]{2}{*}{ Total } \\
\hline & & & Pos & Neg & \\
\hline \multirow{4}{*}{$\begin{array}{l}\text { Neonatal } \\
\text { Weight }\end{array}$} & Macrosome & Count & 40 & 21 & 61 \\
\hline & & $\%$ within Neonatal Weight & $65.6 \%$ & $34.4 \%$ & $100.0 \%$ \\
\hline & Non-Macrosome & Count & 11 & 128 & 139 \\
\hline & & $\%$ within Neonatal Weight & $7.9 \%$ & $92.1 \%$ & $100.0 \%$ \\
\hline \multirow[t]{2}{*}{ 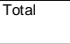 } & & Count & 51 & 149 & 200 \\
\hline & & $\%$ within Neonatal Weight & $25.5 \%$ & $74.5 \%$ & $100.0 \%$ \\
\hline
\end{tabular}

\section{DISCUSSION}

Hemorrhoid existed in 30 percent of people in pre-pregnancy phase and this level was around $35 \%$ one month after childbirth. Fissure was observed among $20 \%$ of people in pre-pregnancy phase and this level reached 25.5 percent one month after childbirth.

This study showed significant relationship between Anorctal disorders after childbirth and the following cases:

a) Number of previous childbirths

Table 2. The relationship between previous childbirth type and Hemorrhoid

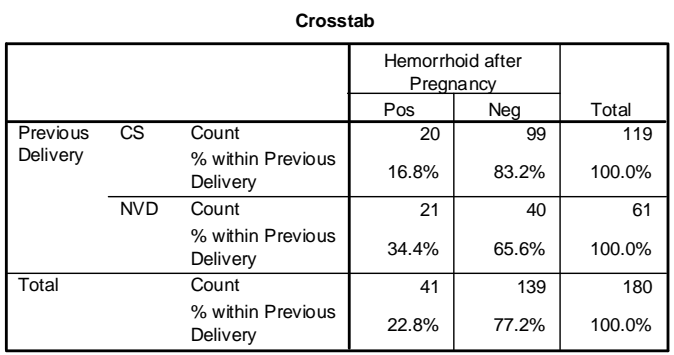

Table 4. The relationship between current childbirth type and Hemorrhoid

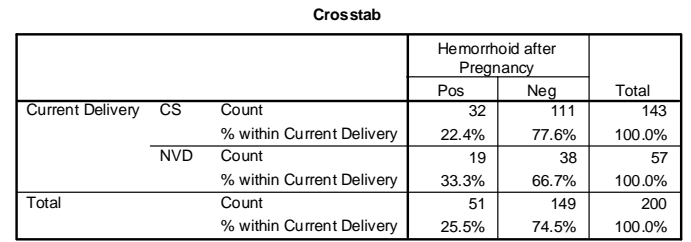

Table 6. The relationship between the length of second phase of Liber and Hemorrhoid

\begin{tabular}{|c|c|c|c|c|c|}
\hline \multicolumn{6}{|c|}{ Crosstab } \\
\hline & & & \multicolumn{2}{|c|}{$\begin{array}{l}\text { Fissure after } \\
\text { Pregnancy }\end{array}$} & \multirow[b]{2}{*}{ Total } \\
\hline & & & Pos & Neg & \\
\hline \multirow{4}{*}{$\begin{array}{l}\text { Second Stage } \\
\text { Duration }\end{array}$} & $<50$ & Count & 12 & 36 & 48 \\
\hline & & $\begin{array}{l}\% \text { within Second } \\
\text { Stage Duration }\end{array}$ & $25.0 \%$ & $75.0 \%$ & $100.0 \%$ \\
\hline & $>50$ & Count & 7 & 2 & 9 \\
\hline & & $\begin{array}{l}\% \text { within Second } \\
\text { Stage Duration }\end{array}$ & $77.8 \%$ & $22.2 \%$ & $100.0 \%$ \\
\hline \multirow[t]{2}{*}{ Total } & & Count & 19 & 38 & 57 \\
\hline & & $\begin{array}{l}\text { \% within Second } \\
\text { Stage Duration }\end{array}$ & $33.3 \%$ & $66.7 \%$ & $100.0 \%$ \\
\hline
\end{tabular}


b) Type of the previous childbirth (Cesarean or natural)

c) Past records of anal disorders

d) Weight of infant

e) Length of the second phase of natural childbirth

No significant relationship was observed in this study between type of the current childbirth and Anorectal disorders, while a larger group of people in the natural childbirth group were afflicted with Fissure and Hemorrhoids.

In a research conducted in Italy whose results were published in 2007, 165 Gynecologists were asked to hand in the information associated

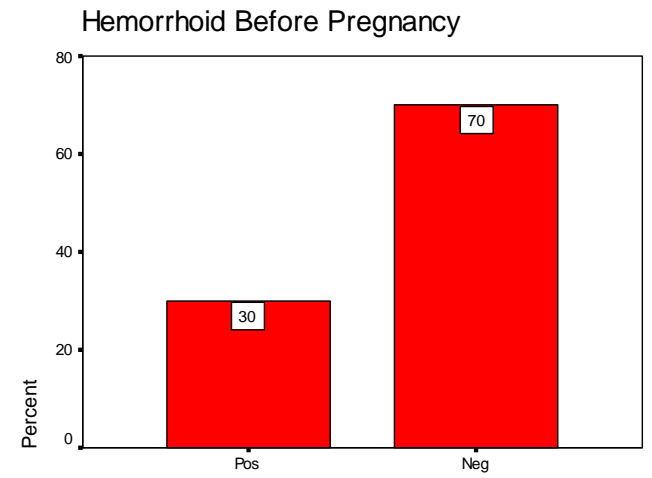

Hemorrhoid Before Pregnancy with the prevalence and treatment of Hemorrhoid among their patients. In this study, the prevalence of post-childbirth Hemorrhoid was 32\% among which $41 \%$ had natural child delivery and 59\% had interventional vaginal childbirth (19). The prevalence of Hemorrhoid in our study was as much as the above mentioned numbers (35\%). The point of strength in that study as compared with ours is the comparison made between two childbirth methods. It shows that using interventional tools promotes the chances of Hemorrhoid. This can be due to the excessive pressure of interventions on Anogenital or secondary area as a result of utilizing interventional tools (such as abnormal

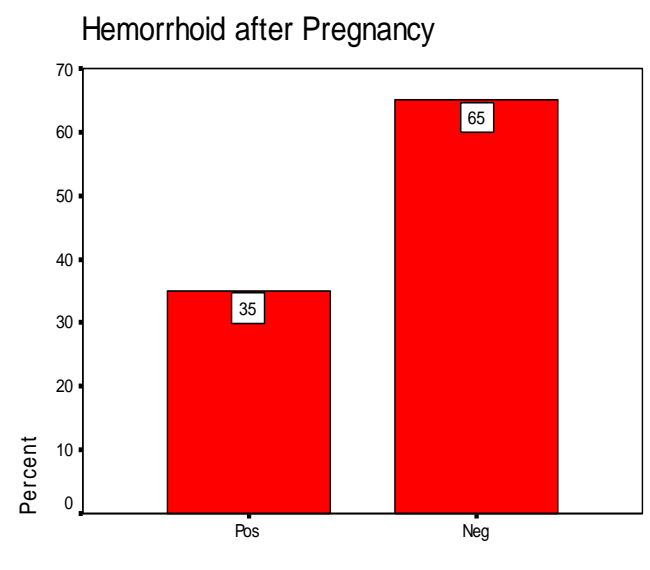

Hemorrhoid after Pregnancy

Fig. 1-2. Levels of Hemorrhoid after and before pregnancy

Fissure Before Pregnancy

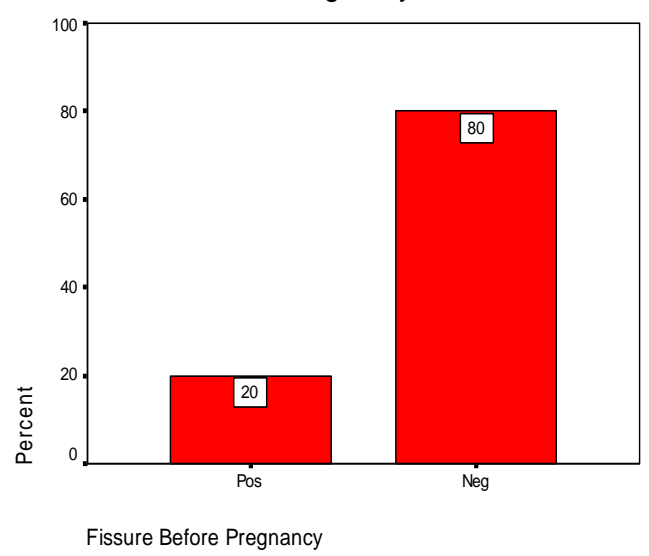

\section{Fissure after Pregnancy}

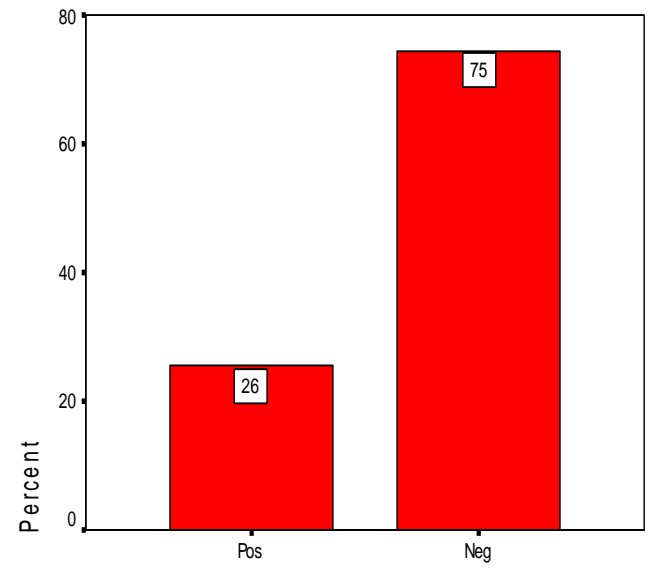

Fissure after Pregnancy

Fig. 3-4. Prevalence of Fissure before pregnancy and one month after childbirth 
presentation which increases the pressure inside the pelvis).

In a study conducted in Paris whose results were published in 2003, anal complications epidemiology during pregnancy and after that was studied. This study stated that $15 \%$ of women experience Fissure in post-childbirth period. Based on the results, $12 \%$ of women experience Fissure in the last three months of pregnancy while $15.2 \%$ are afflicted with Fissure in post-childbirth phase. Furthermore, the rate of external thrombosed hemorrhoid has been reported to range from $12.2 \%$ to $34 \%$ (20). Of course, the prevalence of Hemorrhoid and Fissure in our study was much more than the rate reported above. We didn't study the prevalence of thrombosed hemorrhoid in our research. High levels of external thrombosed hemorrhoid during pregnancy can be due to the excessive rise in the pressure inside the pelvis and rectal veins (5 and 6). As this disease causes severe pain, paying special attention to it during pregnance is a necessity.

In another study conducted in Paris whose results were published in 2002, 165 pregnant women were analyzed during the third three months of pregnancy and also in post-childbirth phase. 9.1\% had anal complications during pregnancy which included 13 cases of Hemorrhoid and 2 cases of Fissure. This rate reached a level of $35.2 \%$ in post-childbirth period which included 33 cases of external Hemorrhoid and 35 cases of Fissure (21). The prevalence rate of Hemorrhoid and Fissure in the above mentioned study was close to our research. Using a bigger sample in our study as compared to the above mentioned study is our point of strength.

In a study conducted in Australia whose results were published in 1997, 1193 women were checked. 13 to $30 \%$ of them were afflicted with Hemorrhoid. The above mentioned study mentions more urinal problems in the group which had undergone Cesarean. However, the prevalence of Hemorrhoid in both groups of Cesarean and naturalchildbirth showed no significant statistical difference ${ }^{11}$.

In a study conducted in Turkey whose results were published in 2010, it was stated that the prevalence of Hemorrhoid during pregnancy and in post-childbirth period is more than the general population of pregnancy-age women. It was shown that the importance of checking this problem and treating the symptoms in pregnant women is really high ${ }^{8}$.

In a study conducted in Canada in 2008 whose results were published in 2008, it was stated that increasing the abdominal pressure and hormonal changes are two major causes of higher rates of Hemorrhoid during pregnancy, especially when NVD childbirth method is utilized. Hemorrhoid was observed in 25 to 35 percent of pregnant women ${ }^{9}$. The prevalence of hemorrhoid in our study is as much as the above mentioned levels, but its level in natural childbirth is not significantly higher than Cesarean.

As mentioned previously, the prevalence of Anorectal disorders in our study was much more than the majority of the studies conducted so far. Reasons such as using traditional Iranian toilets rather than toilet compacts, less frequent use of chairs while sitting, obesity among Iranian mothers, using older Iron supplements which increase chances of constipation and diets with lower levels of fiber may contribute to high rates of Anorectal disorders.

On the other hand, anal blood loss due to Hemorrhoid and Fissure may result in Anemia and Iron deficiency and its consequences will be seen in the future of the infant. Concerning this issue and Anemia and iron deficiency in most mothers, Anorectal disorders during the pregnancy period demand special attention from doctors during pregnancy.

The point of strength in our study is the bigger sample we use compared to previous researches. This research exhibits less quantitative error as it was done in multiple therapeutic centers. The points of weakness in this study may be ignoring the weight of mothers, ignoring the length of pregnancy as a variable, investigating the type of Episiotomy as a variable and checking the patients in the periods much further from childbirth.

Exclude criteria: Severe obesity of mother; preterm delivery of child, term delivery of child

\section{ACKNOWLEDGEMENTS}

Hereby, we would like to thank all midwives of Golest, Khanevade and Besat hospitals who helped us conduct this research. 


\section{REFERENCES}

1. Johanson JF, Sonnenberg A. The prevalence of hemorrhoids and chronic constipation. An epidemiologic study. Gastroenterology. 1990; 98(2):380-6.

2. Grucela A, Salinas H, Khaitov S, et al. Prospective analysis of clinician accuracy in the diagnosis of benign anal pathology: comparison across specialties and years of experience. Dis Colon Rectum. 2010; 53(1):4752.

3. Hosking SW, Smart HL, Johnson AG, et al. Anorectal varices, haemorrhoids, and portal hypertension. Lancet. 1989; 1(8634): 349-52.

4. Bernstein WC. What are hemorrhoids and what is their relationship to the portal venous system?. Dis Colon Rectum. 1983; 26(12): 82934.

5. Johansen K, Bardin J, Orloff MJ. Massive bleeding from hemorrhoidal varices in portal hypertension. JAMA. 1980; 244(18):2084-5.

6. Katz JA, Rubin RA, Cope C, et al. Recurrent bleeding from anorectal varices: successful treatment with a transjugular intrahepatic portosystemic shunt. Am J Gastroenterol. 1993; 88(7):1104-7.

7. Moesgaard F, Nielsen ML, Hansen JB, et al. High-fiber diet reduces bleeding and pain in patients with hemorrhoids: a double-blind trial of Vi-Siblin. Dis Colon Rectum. 1982; 25(5): 454-6.

8. Johanson JF, Rimm A. Optimal nonsurgical treatment of hemorrhoids: a comparative analysis of infrared coagulation, rubber band ligation, and injection sclerotherapy. Am J Gastroenterol. 1992; 87(11):1600-6.

9. El Nakeeb AM, Fikry AA, Omar WH, et al. Rubber band ligation for 750 cases of symptomatic hemorrhoids out of 2200 cases. World J Gastroenterol. 2008; 14(42): 6525-30.

10. Esser S, Khubchandani I, Rakhmanine M. Stapled hemorrhoidectomy with local anesthesia can be performed safely and cost- efficiently. Dis Colon Rectum. 2004; 47(7): 1164-9.

11. Koning MV, Loffeld RJ. Rectal bleeding in patients with haemorrhoids. Coincidental findings in colon and rectum. Fam Pract. 2010 [In Press].

12. Salvati EP. Management of acute hemorrhoidal disease. Perspect Colon Rectal Surg. 1990; 3: 309-14.

13. Nzimbala MJ, Bruyninx L, Pans A, et al. Chronic anal fissure: common aetiopathogenesis, with special attention to sexual abuse. Acta Chir Belg. 2009; 109(6): 720-6.

14. Gibbons CP, Read NW. Anal hypertonia in fissures: cause or effect?. Br J Surg. 1986; 73(6): 443-5.

15. Sileri P, Stolfi VM, Franceschilli L, et al. Conservative and Surgical Treatment of Chronic Anal Fissure: Prospective Longer Term Results. J Gastrointest Surg. 2010. [In Press]

16. Lewis TH, Corman ML, Prager ED, Robertson WG. Long-term results of open and closed sphincterotomy for anal fissure. Dis Colon Rectum. 1988; 31(5): 368-71.

17. Rosen L, Abel ME, Gordon PH, et al. Practice parameters for the management of anal fissure. The Standards Task Force American Society of Colon and Rectal Surgeons. Dis Colon Rectum. 1992; 35(2):206-8.

18. Shao WJ, Li GC, Zhang ZK. Systematic review and meta-analysis of randomized controlled trials comparing botulinum toxin injection with lateral internal sphincterotomy for chronic anal fissure. Int J Colorectal Dis. 2010 [In Press].

19. Gaj F, Trecca A, Crispino P. Haemorrhoid disease during pregnancy: focus on delivery unit. Clin Ter. 2007;158(4):285-9.

20. Abramowitz L, Batallan A. Epidemiology of anal lesions (fissure and thrombosed external hemorroid) during pregnancy and post-partum. Gynecol Obstet Fertil. 2003;31(6):546-9.

21. Abramowitz L, Sobhani I, Benifla JL, et al. Anal fissure and thrombosed external hemorrhoids before and after delivery. Dis Colon Rectum. 2002;45(5):650-5. 